\title{
On a Computational Model of the Peircean Semiosis
}

\author{
Antônio Gomes, Ricardo Gudwin \& João Queiroz \\ FEEC-UNICAMP, Cx Postal 6101 - 13081-970 \\ Campinas - SP - Brazil, \\ \{asrgomes, gudwin, queirozj\}@ dca.fee.unicamp.br
}

\begin{abstract}
In this work we propose computational approach to the Peircean triadic model of semiosis (meaning processes). We investigate several theoretical constraints on the feasibility of a simulated semiosis within digital computers. These constraints, which are basic requirements for the simulation of semiosis, refer to the synthesis of irreducible triadic relations (Sign - Object Interpretant). We examine the internal organization of the triad, that is, the relative position of its elements and how they relate to each other by determinative relations. We also suggest a computational approach based on selforganization principles. In this context, relations of determination are described as emergent properties of the system.
\end{abstract}

\section{INTRODUCTION}

Computational-based methodologies have been used to design virtual experimental protocols, where it is possible to simulate the predictions derived from theoretical models [1, 2], in particular those describing semiotic processes in artificial systems. Computer simulations can be used to study different levels of the organization of semiotic processes $[3,4,5]$. These levels include the simulation of syntactic structures $[6,7, \quad 8]$, morpho-syntactic compositionality [9], lexicalization phenomena [10, 11, 12, 13], symbolic competence [14], communication [15, 16, 17, $18]$, and meaning creation in communication $[19,20]$.

Here we propose a computational model of C.S. Peirce triadic notion of meaning processes (or semiosis). In order to synthesize artificial systems able to perform some sort of semiosis, we

(i) introduce some principles of Peirce's philosophy of sign,

(ii) define the major theoretical constraints required to semiosis simulation,

(iii) specify a computational strategy to implement semiosis according to the aforementioned constraints,

(iv) propose a system implementation in which one can observe emergence of semiotic processes, and

(v) discuss the "state of art" of computational approaches to semiosis.

\section{Principles of Peircean Semiosis}

The Peircean list of logical/phenomenological categories (Firstness, Secondness, Thirdness) constitutes an exhaustive system of hierarchically organized classes of relations (monadic, dyadic, triadic) $\left[21^{1}, 22\right]$. This system is the formal foundation of his architectonic philosophy $\left[23^{2}\right]$ and of his model of semiosis (action of sign) $\left[24^{3}, 25^{4}\right]$. Peirce defined semiosis as an irreducible triadic relation $\left[26^{5}\right]$ between Sign-Object-Interpretant $\left[27,22,28^{6}\right]$. According to Peirce, any description of semiosis involves, in a nonintuitive way $\left[29^{7}\right]$, a relation constituted by three irreducibly connected terms (S-O-I), which are its minimal constitutive elements $\left[28^{7}\right]$.

"A Sign is anything which is related to a Second thing, its Object, in respect to a Quality, in such a way as to bring a Third thing, its Interpretant, into relation to the same Object, and that in such a way as to bring a Fourth into relation to that Object in the same form, ad infinitum" $\left[28^{8}\right]$.

For the purpose of this work, we must consider an important sub-division on the nature of the object:

"We must distinguish between the Immediate Object, -- i.e. the Object as represented in the sign, -- and the Real (no, because perhaps the Object is altogether fictive, I must choose a different term, therefore), say rather the Dynamical Object, which, from the nature of things, the Sign cannot express, which it can only indicate and leave the interpreter to find out by collateral experience" $\left[28^{9}\right]$.

In the next section, we investigate these definitions and identify the major theoretical constraints required to simulate semiosis.

\footnotetext{
${ }^{1}$ See $\$ 14$.

${ }^{2}$ See $\$ 60$.

${ }^{3}$ See $\$ 303-306$.

${ }^{4}$ See $\$ 448$.

${ }^{5}$ See $\$ 2: 171$

${ }^{6}$ See $\$ 1.363$, $\$ 8.331$, and $\$ 7.537$.

${ }^{7}$ See pages $69-70$

${ }^{7}$ See $\$ 2.242$ and $\$ 2.274$

${ }^{8}$ See $\$ 2.92$.

${ }^{9}$ See $\$ 8.314$ and $\$ 8.343$.
} 


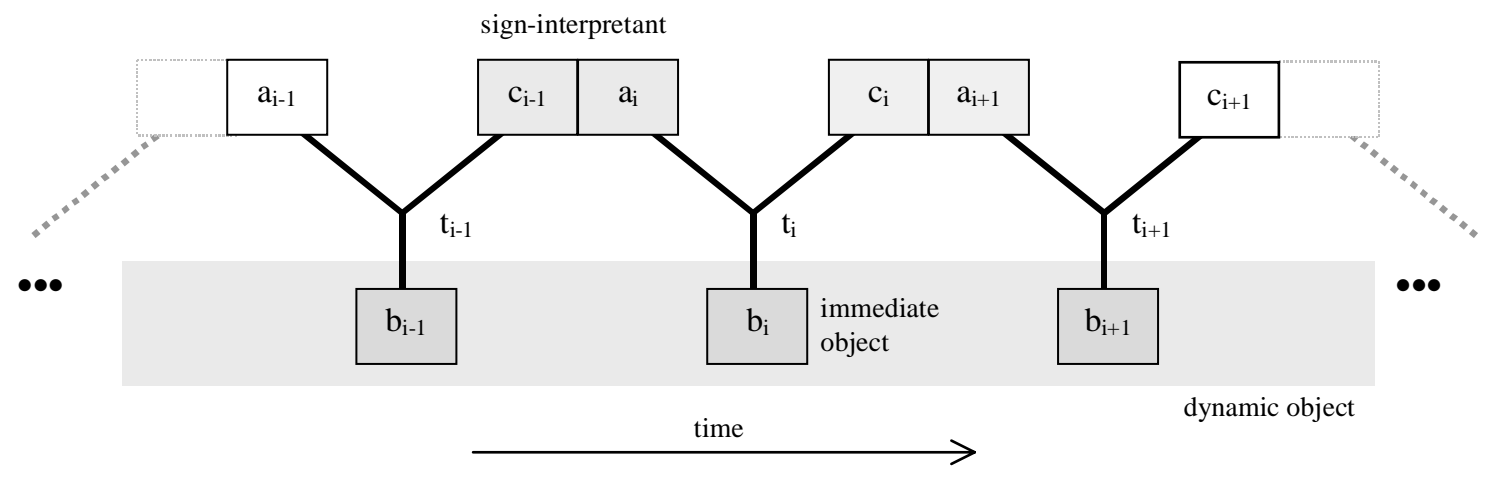

Figure 1 - Model of relative positions of S-O-I

\section{Peircean Semiotics Constraints}

We divide the theoretical constraints into two sections. The first investigates the relative positions and the second the relations of determination between terms.

\subsection{Relative positions of $\mathrm{S}$-O-I}

Let a chain of triads be $\mathrm{T}=\left\{\ldots, \mathrm{t}_{\mathrm{i}-1}, \mathrm{t}_{\mathrm{i}}, \mathrm{t}_{\mathrm{i}+1}, \ldots\right\}$, where $\mathrm{t}_{\mathrm{i}}=\left(\mathrm{a}_{\mathrm{i}}\right.$, $\left.b_{i}, c_{i}\right)$ and $i \in N$. Then the following conditions must hold:

$\forall \mathrm{i}: \mathrm{a}_{\mathrm{i}}=\mathrm{c}_{\mathrm{i}-1}$

$\exists \mathrm{d} \forall \mathrm{i}$ : ImmediateObject $\left(\mathrm{b}_{\mathrm{i}}, \mathrm{d}\right)$

where the logic predicate ImmediateObject $\left(b_{i}, d\right)$ denotes that $b_{i}$ is an immediate object of a dynamic object $d$. It is of paramount importance to notice that the equality expressed in Equation 3.1 means that, in fact, $\mathrm{c}_{\mathrm{i}-1}$ and $\mathrm{a}_{\mathrm{i}}$ are just aliases for the same thing $-c_{i-1}$ and $a_{i}$ are roles played by this "thing" within triads $t_{i-1}$ and $t_{i}$ respectively.

The constraints represented by equations 3.1 and 3.2 mean that, given any triad $t_{i}=\left(S_{i}, O_{i}, I_{i}\right)$ in a chain $\mathrm{T}$ :

1. its first term $\left(\mathrm{S}_{\mathrm{i}}\right)$ must be equals to the third term of the preceding triad $\left(\mathrm{I}_{\mathrm{i}-1}\right)$

2. there exists a least one dynamic object (whole gray area at the bottom in Figure 1) such that all second terms $\left(\mathrm{O}_{\mathrm{i}}\right)$ are immediate objects of it,

3. its third term $\left(I_{i}\right)$ must be equals to the first term of the subsequent triad $\left(\mathrm{S}_{\mathrm{i}+1}\right)$, and

4. a triad $t_{i}=\left(\mathrm{S}_{\mathrm{i}}, \mathrm{O}_{\mathrm{i}}, \mathrm{I}_{\mathrm{i}}\right)$ can only be defined as such in the context of a chain of triads $T=\left\{\ldots, t_{i-1}, t_{i}\right.$, $\left.\mathrm{t}_{\mathrm{i}+1}, \ldots\right\}$.

First terms are Signs, Second terms $\left(\mathrm{O}_{\mathrm{i}}\right)$ are Objects, and Third terms are interpretants.

\subsection{Relations of determination}

Determination provides the way the triad elements are arranged to form a sign. According to Peirce:
"The sign is determined by the object relatively to the interpretant, and determines the interpretant in reference to the object in such a way as to cause the interpretant to be determined by the object through the mediation of the sign" (MS 318:81).

These determinations can be rewritten as:

i. O determines $\mathrm{S}$ relatively to I

ii. S determines I relatively to $\mathrm{O}$

According to Ransdell $\left[30^{10}\right]$, determination encompasses a both causal and logical idea. In this context, how do these causal and logical modes operate? What does a triadic relation expressed as ' $X$ determines $Y$ relatively to $Z$ ' means? A computational approach to this problem will be provided in the following sections.

\section{Preliminary Approach to Semiosis}

Consider the assumption that semiosis is a dynamical process that happens in time. Hence, each new triad is appended at the end of the chain of triads, according the constraints given in Section 3, that is:

$$
\ldots \rightarrow\left(\mathrm{S}_{\mathrm{i}-1} \mathrm{O}_{\mathrm{i}-1} \mathrm{I}_{\mathrm{i}-1}\right) \rightarrow\left(\mathrm{S}_{\mathrm{i}} \mathrm{O}_{\mathrm{i}} \mathrm{I}_{\mathrm{i}}\right) \rightarrow\left(\mathrm{S}_{\mathrm{i}+1} \mathrm{O}_{\mathrm{i}+1} \mathrm{I}_{\mathrm{i}+1}\right) \rightarrow \ldots
$$

We propose that semiosis operates at two distinct levels that, together, may provide a more comprehensible treatment to synthetic approaches:

At the higher level, here designated by macro-semiosis, chains of triads are created and evolved. Each chain possesses some crucial properties, such as being potentially infinite (unlimited semiosis) and always referring to the same object. In the work of Peirce and many of his followers, this is the closest we get to the understanding of semiosis as a dynamic process happening in time. On the other hand, from a computational viewpoint, this resolution per se does not provide a suitable knowledge on how to effectively realize the evolution of chains in a computer.

\footnotetext{
${ }^{10}$ See $\$ 23$.
} 


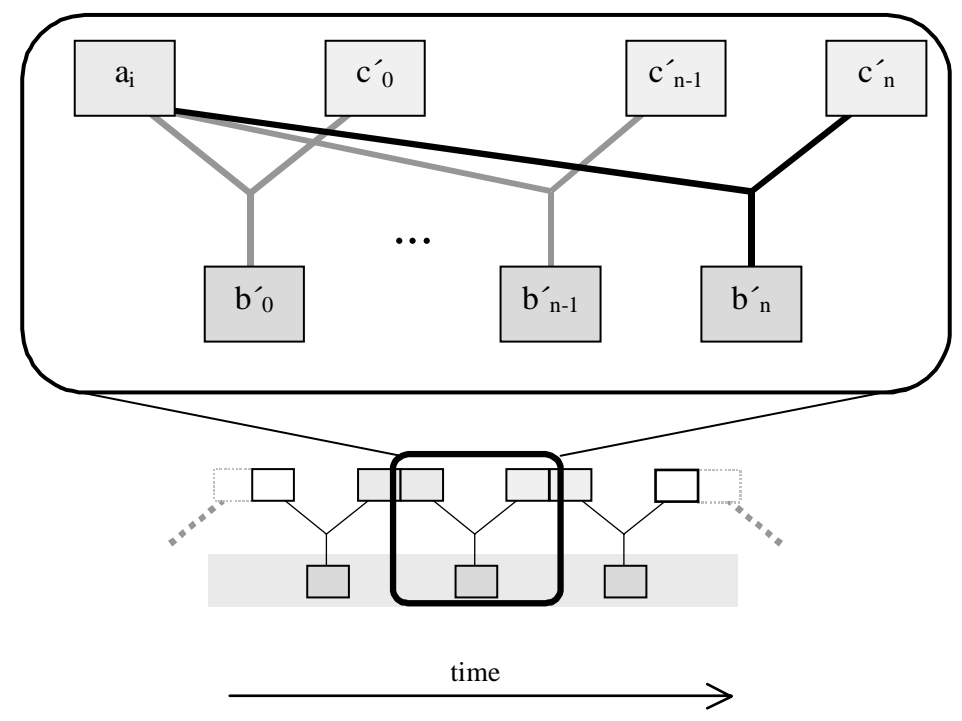

Figure 2 - Macro-semiosis (bottom) and micro-semiosis (top).

As a result of the aforementioned arguments, there is a motivation for the proposal of a lower level, here designated by micro-semiosis, that focuses on how relations of determination are computationally created inside the triad itself (see Figure 2).

Micro-semiosis refer to each simulation step in the process of signification, that is, the realization of the triadic relation within triads. An important consequence is that S-O-I triadic relations are not necessarily created in atomic steps. This view is suitable to the implementation of computational strategies, as most techniques (neural networks, genetic algorithms, etc.) are based on iterative algorithms.

A relation of determination may be, in this sense, gradually refined until it reaches a minimum trade-off between the computational resources required and the conformity with theoretical constraints.

\section{Proposal For an Algorithm}

This section presents a computational strategy to implement simulated semiosis within digital computers. The iterative algorithm proposed here relies on the notion of macro and micro-semiosis stated earlier. The level of detail provides a general framework in which computational techniques, such as neural networks, genetic algorithms, classifier systems, and so on, can be applied to effectively simulate semiosis.

\subsection{General Definitions}

For the purpose of the present development, an iterative process can be described as an ordered sequence of operations $\left\{A_{1}, A_{2}, \ldots, A_{i}, \ldots, A_{n}\right\}$. Thus, an operation $A_{i}$ can only be performed after $A_{i-1}$, and $A_{i-2}$ only after $A_{i-3}$, and so on.

Other important definitions and requirements are given. There exist driving constraints: (i) $\mathrm{O}$ is the primary constraining of semiosis, and (ii) $\mathrm{S}$ is the primary agency of semiosis. There are three modalities of relation between a first (Sign) and a second (Object): (i) intrinsic quality of S (first term dependent), (ii) S-O relational quality (firstsecond relation dependent), and (iii) imputed quality by I to $\mathrm{S}-\mathrm{O}$ (third term dependent).

Definition 5.1: A potential sign, in the course of an iterative process, is something that may be the sign of an object (stand for) to an interpretant.

Definition 5.2: A potential object, in the course of an iterative process, is something that may be the Object of a Sign to an interpretant.

Definition 5.3: A potential interpretant, in the course of an iterative process, is something that may be the interpretant of a Sign (stand to).

A potential sign becomes a sign only when submitted to a mediative relation of determination between Object and Interpretant. Being determined by the Object, the Sign is constrained by it. This means that the Sign can only assume its role as a Sign if attested as such by the Object. Determining the interpretant, the Sign constrains it. 


\subsection{Algorithm}

Consider the statements: (i) $\mathrm{O}$ determines $\mathrm{S}$ relatively to $\mathrm{I}$, (ii) $\mathrm{S}$ determines I relatively to $\mathrm{O}$. Arbitrarily, lets start by the first statement. From a computational point of view, the first question is: which one of the terms comes first in time? If we read determination as a causal process we are tempted to state that $S=f(O, I)$. One of the problems with this view is that $\mathrm{O}$ is not available before $\mathrm{S}$, and $\mathrm{I}$ is not available before $\mathrm{O}^{11}$. The fact that $\mathrm{O}$ determines $\mathrm{S}$ relatively to $\mathrm{I}$ means that $\mathrm{S}$ assumes its condition because of $\mathrm{O}(\mathrm{O}$ causes $\mathrm{S})$ and I, but does not mean that either $\mathrm{O}$ or I are available. This affirmation may lead us to a sort of dead-end because it provides no starting point. However, if determination is seen as a logical-causal constraint there may be alternative ways to perform this process.

Assume that $\mathrm{S}^{\prime}$, which is available at time $\mathrm{t}$, is a potential sign. $S^{\prime}$ has an interpretive potential, that is, the faculty of being potentially interpretable (I) as a Sign of something (an Object). Then, we need to find an Object $\mathrm{O}^{\prime}$ and an Interpretant $I^{\prime}$ that assumes a triadic relation with $S^{\prime}$. If the theoretical constraints (Section 3) are satisfied, we can then say that they form a sign (at a time $t^{\prime}>t$ ).

We propose an algorithm to perform micro-semiosis. It presupposes the notion of environment and agent. The synthetic environment represents the reality that is forced upon the agent's sensors. The environment is infinitely complex (from the viewpoint of the agents ${ }^{12}$ ). Agents, which are immersed in the environment, are able to perceive and act on the environment.

The steps of the algorithm are as follows:

1. Choose a collection of potential signs $\mathrm{PS}=\left\{\mathrm{S}_{\mathrm{i}}^{\prime}\right\}$;

2. Choose one potential sign $\mathrm{S}^{\prime}$ from this collection;

3. Propose a potential object $\mathrm{O}^{\prime}$ and a potential interpretant $I^{\prime}$, such that there exists a relation in one of the three possible modes (see above for intrinsic, relational and imputed qualities). Then, we say that $\mathrm{O}^{\prime}$ determines $\mathrm{S}^{\prime}$ relatively to $\mathrm{I}^{\prime}$.

Comments about the algorithm:

- The collection of potential signs may encompass virtually everything available in the system, as anything can be seen as a sign (see Figure 3);

- The selection of a potential sign may sound somewhat arbitrary, as one may suppose that it is just a matter of time to find a suitable relation with a chosen $\mathrm{O}$. However, it is quite reasonable to propose some sort of selection mechanism to increase the effectiveness;

- $\quad$ Step 3 is the most difficult of all, because it requires some sort of emergent behavior. Emergence, by its own, cannot be achieved atomically, that is, it demands

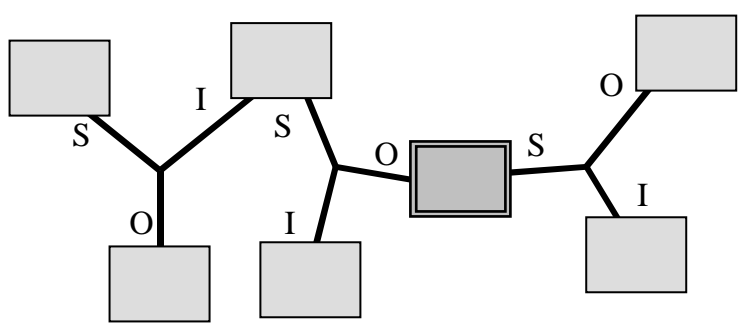

Figure 3-Semiotic nature of elements, in which everything may be interpreted as a sign.

many separated steps that are performed sequentially in time (an iterative process). In this case, many candidate pairs are proposed and selected. Possibly, there must be some sort of fitness measure to guide this process.

- The potential objects are things that are available in the environment, through the mechanisms of perception. They are things that exist; they are things that turn into Objects from Signs.

In order to implement this algorithm one must first define some sort of cognitive architecture for the agent, in which sensors and effectors are specified. Many details were left out. The goal of this proposal is to state very basic steps to perform simulated semiosis.

\section{Conclusions}

Currently, there is no tractable computational model based on a strict definition of Peirce's semiosis. Many other researches, however, based on other notions of semiosis, have been proposed to simulate sign processes in computers $[31,32,33,34]$.

This research, which is a work in progress, strives for a solid understanding on how to simulate Peircean semiosis (meaning processes) within digital computers. We have shown in this article a brief overview of the Peircean semiotics, and pointed out two fundamental constraints that are required to simulate semiosis, namely, the relative position of triad elements and the relations of determination between them. Based on these constraints, we proposed a general algorithm to accomplish artificial semiosis. This algorithm derives from the notion of macro and microsemiosis. This proposal still lacks many details, but sketches a general framework to design experimental semiotic systems.

Further developments will include a more detailed algorithm and an implementation of artificial semiosis in a computer.

\footnotetext{
${ }^{11}$ From Figure 1, we can see that $S_{i}\left(a_{i}\right.$ in the $i-t h$ triad) is obtained from $I_{i-1}$ ( $\mathrm{c}_{\mathrm{i}-1}$ in the preceding triad in the same chain).

${ }^{12}$ This means that the agent is able to perceive only part of its "reality".
} 


\section{REFERENCES}

[1] Bedau, M. A. (1998). Philosophical content and method of artificial life. In Bynam, T. W., \& Moor, J. H. (Eds.), The Digital Phoenix: How Computers are Changing Philosophy (pp. 135-152). Oxford: Basil Blackwell.

[2] Parisi, D. (2001). Simulazioni - la realtà rifatta nel computer. Bologna: IlMulino.

[3] Cangelosi, A \& Turner, H. (2002). L'emergere del linguaggio. In Borghi, A. M., \& Iachini, T. Scienze della Mente (pp.227-244). Bologna: Il Mulino..

[4] Parisi, D. \& Cangelosi, A. (2002). A unified simulation scenario for language development, evolution and historical change. In Cangelosi, A., \& Parisi, D. (Eds.). Simulating the Evolution of Language (pp. 255-329). London: Springer Verlag.

[5] Perfors, A. (2002) Simulated evolution of language: A review of the field. Journal of Artificial Societies and Social Simulation 5(2).

[6] Batali, J. (1994). Innate biases and critical periods: Combining evolution and learning in the acquisition of syntax. In Brooks, R., \& Maes, P. (Eds.), Artificial life IV (pp.160-171). Cambridge, Mass.: MIT Press.

[7] Batali, J. (1998). Computational simulations of the emergence of grammar. In Hurford, J. R., StuddertKennedy, M., \& Knight, C.(Eds.), Approaches to the Evolution of Language - Social and Cognitive Bases (pp. 405-426). Cambridge: Cambridge University Press.

[8] Kirby, S. (1999). Learning, bottlenecks and infinity: a working model of the evolution of syntactic communication. In Dautenhahn, K. \& Nehaniv, C. (Eds.) Proceedings of the AISB'99 Symposium on Imitation in Animals and Artifacts (pp. 55-63). Cambridge: Cambridge University Press.

[9] Ellefson, M. R., \& Christiansen, M. H. (2002). Linguistic adaptation without linguistic constraints: The role of sequential learning in language evolution. In Wray, A. (Ed.), The Transition to Language (pp. 335-358). Oxford: Oxford University Press.

[10] Hurford, J. (1991). The evolution of the critical period for language acquisition. Cognition 40(3), 159-201.

[11] Steels, L. (1999). The Talking Heads Experiment: Volume I. Words and Meanings. Pre-Edition. VUB Artificial Intelligence Laboratory, LABORATORIUM, Antwerpen.

[12] Cangelosi, A., \& Parisi, D. (1998). The emergence of a language in an evolving population of neural networks. Connection Science, 10(2), 83-97.

[13] Steels, L, Kaplan, F, MCintyre, A, Van Looveren, J. (2002). Crucial factors in the origins of word-meaning. In Wray, A. (Ed.), The Transition to Language (pp. 252-271). Oxford: Oxford Press.

[14] Cangelosi, A. (2001). Evolution of communication and language using signals, symbols, and words. IEEE Transactions on Evolutionary Computation, 5(2), 93-101.
[15] Hutchins, E., \& Hazlehurst, B. (1995). How to invent a lexicon: the development of shared symbols in interaction. In Gilbert, G. N., \& Conte R. (Eds.), Artificial Societies: The Computer Simulation of Social Life. London: UCL Press.

[16] Steels, L. (1997). The synthetic modeling of language origins. Evolution of Communication 1(1), 1-37.

[17] Steels,L. \& Kaplan, F. (1999). Situated grounded word semantics In Dean, T. (Ed), IJCAI'99 Proceedings of the 16th International Joint Conference on Artificial Intelligence (vol.2, pp. 862-867). San Francisco, CA: Morgan Kaufmann Publishers.

[18] Kvasnicka, V., \& Pospichal, J. (1999). An emergence of coordinated communication in populations of agents. Artificial Life 5, 319-342.

[19] MacLennan. B. J. (2001). The emergence of communication through synthetic evolution. In Patel, M., Honavar, V. \& Balakrishnan, K. (Eds.), Advances in the Evolutionary Synthesis of Intelligent Agents (pp. 65-90). Cambridge, Mass.: MIT Press.

[20] Smith, A. D. M. (in press). Intelligent meaning creation in a clumpy world help communication. Artificial Life.

[21] Houser, N. (1997). Introduction: Peirce as a logician. In Houser, N., Roberts, D., \& Evra, J. (Eds.) Studies in the logic of Charles Sanders Peirce (pp. 1-22). Indiana: Indiana University Press.

[22] BRUNNING, J. 1997. Genuine triads and teridentity, In: Studies in the logic of Charles Sanders Peirce. (Eds.) N. Houser, D. Roberts, J. Evra. Indiana University Press. pp. 252-270

[23] Parker, K. (1998). The Continuity of Peirce's Thought. Nashville:Vanderbilt University Press

[24] Murphey, M. G. (1993). The Development of Peirce's Philosophy. Indianapolis: Hackett.

[25] Kent, B. (1997). The interconnectedness of Peirce's diagrammatic thought. In Houser, N., Roberts, D., \& Evra, J.(Eds.), Studies in the Logic of Charles S. Peirce (pp. 445459). Indiana: Indiana University Press.

[26] Peirce, Charles S. (EP1, EP2). The Essential Peirce. Selected Philosophical Writings. Vol. 1 (1867-1893) (ed. by Nathan Houser and Christian Kloesel). Vol. 2 (1893-1913) (ed. by the Peirce Edition Project). Bloomington and Indianapolis: Indiana University Press, 1992 and 1998.

[27] BURCH, R. 1991. A Peircean Reduction Thesis. Texas Tech University Press. _. 1997. "Peirce's reduction thesis", In: Studies in the logic of Charles Sanders Peirce. (Eds.) N. Houser, D. Roberts, J. Evra. Indiana University Press. pp. 234-251.

[28] PEIRCE, C.S. 1931-1935. The collected papers of Charles Sanders Peirce. Electronic edition reproducing Vols. I-VI [C. Hartshorne \& P. Weiss (Eds.), Cambridge: Harvard University Press, 1931-1935], Vols. VII-VIII [A. W. Burks (Ed.), same publisher, 1958]. Charlottesville: Intelex Corporation. (Here referred as $\mathrm{CP}$, followed by 
volume and paragraph number.)

[29] Deacon, T. (1997). Symbolic Species: The Co-evolution of Language and the Brain. New York: Norton.

[30] RANSDELL, J. Peircean semiotics, 1983. (unpublished).

[31] Gudwin, R.R. (2001). Semiotic synthesis and semionic networks. In SEE'01 - 2nd International Conference on Semiotics, Evolution and Energy, University of Toronto, Toronto, Canada.
[32] Guerrero, J.A.S, Gomes, A.S.R., \& Gudwin, R.R. (1999). A computational tool to model intelligent systems In Anais do 4o SBAI - Simpósio Brasileiro de Automação Inteligente (pp. 227-232), São Paulo, Brasil.

[33] Meystel, A. M. (1996). Intelligent systems: A semiotic perspective. International Journal of Intelligent Control and Systems, 1(1):31-57.

[34] (POSPELOV 1991) D. Pospelov, "Situational Control: Theory and Practice" - (unpublished translation of the book with the same tittle in russian, from Nauka Publishers, Moscow, 1986). 